DIGITALCOMMONS

@WAYNESTATE -
Michigan Journal of Counseling:

Research, Theory and Practice

Volume 39 | Issue 2

Article 2

$1-1-2013$

\title{
The Ethical Implication of Bartering for Mental Health Services: Examining Interdisciplinary Ethical Standards
}

Joel A. Lane

Oakland University, jalane@oakland.edu

Follow this and additional works at: https://digitalcommons.wayne.edu/mijoc

\section{Recommended Citation}

Lane, J. A. (2013). The Ethical Implication of Bartering for Mental Health Services: Examining Interdisciplinary Ethical Standards, Michigan Journal of Counseling, 39(2), 4-12. doi:10.22237/mijoc/1356998460

This Article is brought to you for free and open access by the Open Access Journals at DigitalCommons@WayneState. It has been accepted for inclusion in Michigan Journal of Counseling: Research, Theory and Practice by an authorized editor of DigitalCommons@WayneState. 


\title{
The Ethical Implication of Bartering for Mental Health Services: Examining Interdisciplinary Ethical Standards
}

Joel A. Lane

Oakland University

\begin{abstract}
The present paper discusses literature concerning the practice of bartering for counseling, psychological, or social work services in lieu of traditional monetary payment. The author contrasts the language concerning the practice of bartering found in the respective ethical codes for each profession, and presents literature describing both risks and potential benefits of bartering arrangements. The primary risks of bartering include liability concerns and the potential for harmful or exploitive dual relationships. The primary benefits are that bartering makes mental health services available to those who cannot afford traditional fees, and allows for a culturally relevant compensation method for those whose cultural backgrounds emphasize the practice of bartering.
\end{abstract}

\section{The Ethical Implications of Bartering for Mental Health Services: Examining Interdisciplinary Ethical Standards}

Across disciplines, helping professionals are charged with offering services, without discrimination, to a diverse client base with respect to gender, sexual orientation, religious beliefs, cultural background, and socioeconomic status (American Counseling Association, 2005; American Psychological Association, 2002; Clinical Social Work Federation, 1997; National Association of Social Workers, 1996). This obligation leads some professionals, in an effort to serve as many clients as possible, to agree to enter into unorthodox bartering agreements with some clients who either cannot afford the professional's fees or whose cultural background emphasizes the use of barter transactions (Thomas, 2002; Zur, 2008).

With the exception of the Psychology profession (American Psychological Association, 2002), the ethical standards of the various helping professions discourage the practice of bartering because of the resulting dual relationship it creates between practitioner and client (American Counseling Association, 2005; Clinical Social Work Federation, 1997; National Association of Social Workers, 1996). These standards, however, also offer guidelines to determine when such an arrangement might be appropriate. Literature on the subject of

Joel A. Lane is a doctoral candidate in the Counselor Education program at Oakland University. Correspondence can be sent to jalane@oakland.edu. 
bartering is both scarce and polarized, as most seem to think the practice either is ill advised and should be entirely avoided (Canter, Bennett, Jones, \& Nagy, 1994; Gutheil \& Gabbard, 1993; Woody, 1998), or has therapeutic potential that, when used sparingly, outweighs the risks (Croxton, Jayaratne, \& Mattison, 2002; Hendricks, 1979; Hill, 2000; Syme, 2006; Thomas, 2002; Zur, 2008).

Given the emphases on multiculturalism and social justice within the counseling profession, counselors would benefit from a discussion outlining the benefits and risks associated with the practice of accepting barters for services. Toward this end, the proceeding discussion reviews the ethical codes of several helping professions as they pertain to the practice of bartering, and examines relevant literature. The purpose of this article is not to advocate for or against the practice of bartering, but rather to review current bartering practices in the literature and provide professionals with information needed to make informed decisions concerning the incorporation of bartering into their scopes of practices.

\section{Glossary of Terms}

There are several constructs in the proceeding discussion warranting definition. In the context of this paper, "bartering" is used to describe the use of goods and/or services as payment for mental health services. The term "mental health services" is used to describe a service such as personal counseling, career counseling, psychotherapy, psychiatric evaluation, social work, or any other service used to improve cognitive, emotional, or relational functioning. The use of the terms "therapy" and "psychotherapy" are meant to describe the practice of any of the aforementioned disciplines, while the term "therapist" refers to any professional practicing psychotherapy.

\section{Comparing Multidisciplinary Ethical Codes}

Bartering is a topic discussed in each of the respective ethical codes of the American Counseling Association (ACA; 2005), the American Psychological Association (APA; 2002), and National Association of Social Workers (NASW; 2008). These associations differ in the strength of the language of bartering guidelines from more restrictive (NASW) to more permissive (APA). The ACA's (2005) stance is that:

Counselors may barter only if the relationship is not exploitive or harmful and does not place the counselor in an unfair advantage, if the client requests it, and if such arrangements are an accepted practice among professionals in the community. Counselors consider the cultural implications of bartering and discuss relevant concerns with clients and document such agreements in a clear written contract. (para. A.10.d.) The NASW Code of Ethics (2008) uses stronger language discouraging the practice of bartering, stating:

Social workers should avoid accepting goods or services from clients as payment for professional services. Bartering arrangements, particularly involving services, create the potential for conflicts of interest, exploitation, and inappropriate boundaries in social workers' relationships with 
clients. Social workers should explore and may participate in bartering only in very limited circumstances when it can be demonstrated that such arrangements are an accepted practice among professionals in the local community, considered to be essential for the provision of services, negotiated without coercion, and entered into at the client's initiative and with the client's informed consent. Social workers who accept goods or services from clients as payment for professional services assume the full burden of demonstrating that this arrangement will not be detrimental to the client or the professional relationship. (para. 1.13b.)

The Clinical Social Work Association (CSWA; Clinical Social Work Federation, 1997) Code of Ethics has similar language, but adds that bartering arrangements "may only involve goods, as opposed to services, in exchange for treatment" (Sec. V, para. d.).

The APA's (2002) stance on bartering is the least restrictive of the three associations and seems to leave the decision of whether or not to barter largely to the discretion of the psychologist: "Barter is the acceptance of goods, services, or other nonmonetary remuneration from clients/patients in return for psychological services. Psychologists may barter only if (1) it is not clinically contraindicated, and (2) the resulting arrangement is not exploitative" (p. 1068). It is worth noting that the previous revision of the APA Code of Ethics contained considerably different and more restrictive language concerning the topic (cf. APA, 1992).

For purposes of comparison, a dissection of the ACA's (2005) stance demonstrates the following conditions for ethically entering a bartering relationship: 1) the arrangement must not be exploitive, 2) the arrangement must not be harmful, 3) the arrangement must not be unfairly advantageous to the counselor, 4) the arrangement must be at the client's request, 5) there must be an accepted precedence for such an arrangement within the community, 6) the arrangement must be openly discussed with the client, and 7) the arrangement must be mutually agreed upon in writing. Conversely, the NASW (2008) seems more discouraging of bartering, particularly when the client barters services as opposed to goods. The NASW also asserts that the bartering arrangement must be essential, implying that inability on the part of the client to pay the social worker's fee is a necessary component. Clearly, the APA is the least restrictive of the three associations, stating only that the arrangement must not be exploitive or clinically inadvisable. This presumably allows 1) the therapist to initiate the idea of a barter, 2) the arrangement to be made absent of a written agreement, 3) the lack of community precedence for such an arrangement, and 4) the arrangement to be made even in the absence of financial need on the part of the client.

\section{Complications of the Bartering Arrangement}

Woody (1998) took a strong stance against the practice of bartering and stated that it is ill advised insofar as it, among other things, exposes the practitioner to various liability concerns. In the event of a lawsuit, it would be relatively easy for a client to bring claims undermining the appropriateness of the arrangement, such as lacking mental competency at the time of a verbal or written 
bartering contract or feeling pressured to reach a bartering agreement as a result of the inherent power differential between psychologist and client.

Additionally, Woody (1998) pointed out that the nature of all dual relationships contains the potential for change as the course of therapy progresses, and therefore any dual relationship, even those that are not initially harmful, are at risk for becoming harmful at some point during therapy. As a result, according to Woody, it is impossible to accurately determine whether any bartering arrangement is contraindicated. Furthermore, many client situations that are contraindicative to the practice of bartering are not always immediately apparent to the counselor at the outset of therapy, which is, presumably, when a bartering arrangement would be agreed upon. As an example, the symptomology consistent with personality disorder diagnoses are not always apparent at the outset of therapy, and yet bartering is almost always clinically contraindicated for individuals suffering from a personality disorder (Woody, 1998).

Other authors (Canter, Bennett, Jones, \& Nagy, 1994; Koocher \& KeithSpiegel, 1998; Peterson, 1996) expanded upon this idea, asserting that the pervasiveness of mental health services clientele with deficits in appropriate boundary maintenance is sufficient to deem all service-to-service bartering to be clinically contraindicated. In all but rare exceptions, services potentially of value to a counselor, psychologist, or social worker necessitate varying levels of intimate interaction with the professional's personal life. Examples of service barters in the literature included house painting (Peterson, 1996), babysitting (Canter et al., 1994), musical instrument lessons (Hendricks, 1979), office assistance (Thomas, 2002), automobile repair (Zur, 2008), income tax accounting (Haas, Malouf, \& Mayerson, 1986), and full body massages (Hendricks, 1979). Such services expose the counselor to the client in complex ways that can be problematic for clients who are seeking therapeutic services due to problems that often involve inappropriate boundaries in their personal lives.

Further complicating the issue is the potential for therapist dissatisfaction with the service being bartered (Syme, 2006). It is possible that clients may not fulfill their agreed-upon obligations (Thomas, 2002) or may perform work that the therapist views as substandard (Woody, 1998), and these potentialities make for complex and problematic therapeutic interactions (Zur, 2008). In these situations, the therapist may feel that voicing dissatisfaction or disengaging from the bartering agreement would interfere with therapy (Zur, 2008), and therefore feel pressured to continue with the arrangement despite the dissatisfaction. Such complexities and pressures could easily harm the therapeutic relationship, resulting in a multidisciplinary consensus that service-for-service bartering should be avoided (Canter et al., 1994; Croxton et al., 2002; Haas, Malouf, \& Mayerson, 1986; Koocher \& Keith-Spiegel, 1998; Peterson, 1996; Syme, 2006; Woody, 1998).

\section{Potential Benefits for Clients}

These objections notwithstanding, several authors have contended that there are potential benefits of bartering that justify its occasional use. Many individuals in need of therapy services are unable to afford the fees. Compounding this issue are the recent economic hardships and the increase in the unem- 
ployed that have resulted in many individuals in need of therapy but lacking the income or insurance to cover the expense of weekly therapy sessions. This has led some authors (Hill, 2000; Thomas, 2002; Zur, 2008) to contend that refusing to barter can be a form of discrimination that prevents all but the affluent from receiving the treatment they need.

To illustrate the disparity that can exist between the need for counseling and the monetary means to secure it, Thomas (2002) described his clinical work as a neuropsychologist specializing in the treatment of individuals with mild brain injuries. The individuals he reported treating often appear to have normal functioning capabilities because of the mild nature of their injuries and therefore are frequently expected to function effectively in society without extra accommodations. As a result, many of these individuals frequently are unable to maintain employment since employers hold them to the same performance standards as other employees. For these uninsured and unemployed individuals, Thomas has made occasional use of bartering agreements.

Other authors (Croxton et al., 2002; Hill, 2000; Syme, 2006; Zur, 2008) mentioned the cultural implications of accepting barter. In some rural or agricultural communities, bartering with neighbors and with community professionals is common practice. Therapists within those communities should be allowed to barter as long as all necessary ethical precautions are taken (Croxton et al., 2002). In working with culturally diverse clients, Syme (2006) noticed that accepting barters from those for whom bartering is a culturally emphasized practice can be therapeutically beneficial in that it portrays the practitioner as valuing of the client's background.

Zur (2008) asserted that accepting handmade goods produced by a client (e.g., paintings, sculptures, meals, etc.) can be empowering because it sends a message that the client is capable of producing something of value. Zur recalled a specific example in which an artist traded him a painting in exchange for 10 therapy sessions. According to Zur, having the painting hanging in the office during their sessions was one factor contributing to a deep therapeutic connection with that client. Thomas (2002) agreed, stating that he has often noticed enhanced client investment in the treatment process when the client is producing goods that are used to pay for therapy sessions.

It is important to note that each of these proponents advocated taking specific precautions whenever considering making a bartering arrangement. These precautions are consistent with the stipulations expressed in the ethical codes and are meant to protect both the client from potential exploitation and harm and the therapist from ethical or legal liability. Some of the general precautions include: 1) considering the potential complications as well as transference or countertransference issues that may arise prior to agreeing to the bartering arrangement (Zur, 2008); 2) engaging in open dialogue with the client about the risks and potential complications prior to an agreement (Thomas, 2002); 3) seeking agreement by both parties in the forms of a written contract outlining the bartering terms and an informed consent (Hill, 2000; Thomas, 2002; Zur, 2008); 4) involving the client as an active member of the negotiation process (Zur, 2008); 5) agreeing to revisit the dialogue openly at any point either party feels the terms of the agreement are not being satisfactorily met (Thomas, 2002); 6) declining barter opportunities with clients for whom present- 
ing concerns suggest the possibility of the presence of Borderline Personality Disorder (Zur, 2008); and 7) allowing the bartering arrangement to be openly and regularly scrutinized by the therapist's professional colleagues (Hill, 2000; Thomas, 2002).

It appears that bartering arrangements, when agreed upon in accordance with the ethical codes of one's profession and after considering these precautions, possess the potential to be therapeutically advantageous for certain clients, particularly those for whom the expense of session fees is prohibitive. Gutheil and Gabbard (1993) asserted that boundary crossings possess the potential to be therapeutically harmful, neutral, or helpful, depending upon contextual factors (it should be noted, however, that Gutheil and Gabbard seemed to discourage all forms of bartering on the grounds that they are confusing and that clinicians could avoid them simply by agreeing to a reduced fee or to pro bono services).

\section{Bartering Arrangements and Ethical Decision-Making}

In weighing whether a barter proposal constitutes a potentially helpful boundary crossing as opposed to an ill-advised boundary violation, clinicians may benefit from considering both ethical principles and also various ethical decision-making models. The ethical principles outlined by Kitchener (1984), including Beneficence (contributing to the well-being of others), Nonmaleficence (doing no harm), Justice (striving for fairness in dealings with all people), Fidelity (promoting honesty and integrity), and Autonomy (holding oneself responsible), could uniquely apply to each case and prove to be the grounds for which a bartering agreement is either agreed to or declined. Ethical decision-making models, such as the approach articulated by Tarvydas (1998), may prove helpful as well. Of particular utility in this regard is the work of Pope and KeithSpiegel (2008). These authors developed models specifically for making boundary-related decisions, understanding common logical errors related to boundary dilemmas, and for intervening when boundary violations become problematic.

Pope and Keith-Spiegel (2008) encouraged a decision-making process in which consideration is given to: 1 ) best- and worst-case scenarios of both crossing and not crossing the boundary; 2) research concerning the particular boundary issue; 3 ) ethical codes, laws, and legislation; 4) the feedback of one or more colleagues; 5) one's own uneasiness about the dilemma; 6) careful description of informed consent to the prospective client; 7 ) referral to another professional if one feels ill suited to work with the client or boundary situation; 8) informed consent specifically relating to the boundary violation; and 9) careful case note documentation of the violation, including theoretical rationale for doing so. The authors also asserted that common errors in navigating this decision-making process included the beliefs that: 1) extra-therapeutic events do not impact the work done in therapy, 2) boundary-crossing behaviors carry the same implications for clients as they would with non-clients, 3) clinician and client understandings of boundaries are similar, 4) any given boundary violation is equally helpful or harmful for all clients, 5 ) the impact of a boundary violation is singular and immediate, 6 ) clinicians will be able to anticipate all potential 
benefits and risks of the violation, and 7) self-disclosure is necessarily therapeutic. Finally, Pope and Keith-Spiegel articulated the following suggestions for boundary violations that become problematic: 1) carefully monitor the situation, 2) "be open and nondefensive" (p. 648), 3) seek honest feedback from one or more colleagues, 4) "listen carefully to the client" (p. 649) and do not make assumptions regarding their feelings about the boundary violation, 5 ) attempt to empathize with the client's viewpoint, 6) consider the steps outlined by Pope and Vasquez (2007) if the violation results in a formal complaint, 7) keep thorough records related to the violation, and 8) consider apologizing. The steps in these processes highlight the need for continual self-reflection, consideration of contextual factors, thorough verbal communication with clients, and clear documentation anytime a bartering arrangement is being considered or has been agreed to.

\section{Conclusions}

Despite differing viewpoints regarding whether or not bartering is a viable option, as well as its general discouragement in the Code's of Ethics for counselors (ACA, 2005) and social workers (Clinical Social Work Federation, 1997; NASW, 2008), there are specific, albeit limited, conditions under which bartering is permitted. There are considerably fewer limitations placed upon psychologists (APA, 2002) for entering into such agreements. Even those who are most outspoken against bartering (e.g., Woody, 1998) agree that it offers a means for clients who would normally be unable to pay for mental health services to engage in therapy. Proponents of bartering arrangements assert that fear of lawsuits is what keeps therapists from considering the idea and that, by refusing to barter on the basis of fear, these therapists are not practicing in accordance with the ethical standard of beneficence because they are denying services to those who would benefit from them but cannot afford their services (Thomas, 2002; Zur, 2008). Clearly there are risks associated with bartering, and professionals should weigh all options when considering the sometimes difficult decision of whether or not to accept barter.

To more thoroughly understand the nuances of such a decision, helping professionals would benefit from future bartering research efforts. A potentially helpful direction in this regard would be to qualitatively examine groups of professionals who have utilized bartering arrangements. While authors of existing literature have offered several accounts of both helpful and harmful bartering experiences, the tendency has been to do so in brief case example formats. By rigorously analyzing detailed accounts of bartering agreements and their outcomes, researchers could potentially identify contextual factors indicative of positive and negative bartering experiences. Professionals would then be more ideally positioned to recognize the potential for problematic bartering agreements and to make increasingly informed decisions compared to what is currently possible.

This literature review has sought to empower professionals with information relevant to the process of considering the acceptance of barters from clients. Regardless of profession, all mental health clinicians are encouraged to carefully and systematically consider the ethical, contextual, and relational 
factors present in any potential bartering arrangement. It seems that engaging in bartering with clients, when done so: 1) sparingly, 2) in accordance with one's professional code of ethics, 3 ) in accordance with the aforementioned precautionary guidelines, and 4) in adherence to boundary-related ethical decisionmaking models, allows the counselor, social worker, or psychologist the opportunity to offer treatment to a more diverse socioeconomic and cultural client base.

\section{References}

American Counseling Association (2005). ACA Code of Ethics: As approved by the ACA Governing Council. Retrieved January 10, 2011, from http:// www.counseling.org/Resources/CodeOfEthics/TP/Home/CT2.aspx

American Psychological Association (1992). Ethical principles of psychologists and code of conduct. American Psychologist, 47(12), 1597-1611. doi:10.1037/0003-066X.47.12.1597

American Psychological Association (2002). Ethical principles of psychologists and code of conduct. American Psychologist, 57(12), 1060-1073. doi:10.1037/0003-066X.57.12.1060

Canter, M. B., Bennett, B. E., Jones, S. E., \& Nagy, T. F. (1994). Ethics for psychologists: A commentary on the APA ethics code. Washington, DC: American Psychological Association.

Clinical Social Work Federation (1997). Clinical Social Work Association Code of Ethics. Retrieved March 20, 2012, from www.clinicalsocialworkassociation.org/about-us/ethics-code

Croxton, T. A., Jayaratne, S., \& Mattison, D. (2002). Social work practice behaviors and beliefs: Rural-urban differences? Advances in Social Work, 3 (2), 117-132.

Gutheil, T. G., \& Gabbard, G. O. (1993). The concept of boundaries in clinical practice: Theoretical and risk-management dimensions. American Journal of Psychiatry, 150(2), 188-196.

Haas, L. J., Malouf, J. L., \& Mayerson, N. H. (1986). Ethical dilemmas in psychological practice: Results of a national survey. Professional Psychology: Research and Practice, 17(4), 316-321. doi:10.1037/07357028.17.4.316

Hendricks, C. G. (1979). Using a barter system in psychotherapy. Psychotherapy: Research and Practice, 16, 116-117. doi:10.1037/h0085865

Hill, M. (2000). Barter: Ethical considerations in therapy. Women \& Therapy, 22 
Kitchener, K. S. (1984). Intuition, critical evaluation and ethical principles: The foundation for ethical decisions in counseling psychology. The Counseling Psychologist, 12(3), 43-55. doi:10.1177/0011000084123005

Koocher, G., \& Keith-Spiegel, P. (1998). Ethics in psychology. New York: Oxford University Press.

National Association of Social Workers (2008). Code of Ethics of the National Association of Social Workers. Retrieved March 20, 2012, from http:// www.naswdc.org/pubs/code/code.asp.

Peterson, C. (1996). Common problem areas and their causes resulting in disciplinary action. In L. J. Bass, S. T. DeMers, J. R. P. Ogloff, C. Peterson, J. L. Pettifor, R. P. Reaves, ... R. M. Tipton (Eds.), Professional conduct and discipline in psychology (pp. 71-89). Washington, DC: American Psychological Association.

Pope, K. S., \& Keith-Spiegel, P. (2008). A practical approach to boundaries in psychotherapy: Making decisions, bypassing blunders, and mending fences. Journal of Clinical Psychology: In Session, 64(5), 638-652. doi:10.1002/jclp.20477

Pope, K. S., \& Vasquez, M. J. T. (2007). Ethics in psychotherapy and counseling: A practical guide ( $3^{\text {rd }}$ ed.). San Francisco, CA: Jossey-Bass/Wiley.

Syme, G. (2006). Fetters or freedom: Dual relationships in counselling. International Journal for the Advancement of Counselling, 28, 57-69. doi:10.1007/s10447-005-8499-7

Tarvydas, V. M. (1998). Ethical decision making processes. In R. R. Cottone \& V. M. Tarvydas (Eds.), Ethical and professional issues in counseling (pp. 144-155). Upper Saddle River, NJ: Prentice-Hall.

Thomas, J. L. (2002). Bartering. In A. A. Lazarus \& O. Zur (Eds.), Dual relationships and psychotherapy. New York: Springer.

Woody, R. H. (1998). Bartering for psychological services. Professional Psychology: Research and Practice, 29(2), 174-178. doi:10.1037/07357028.29.2.174

Zur, O. (2008). Bartering in psychotherapy and counseling: Complexities, case studies and guidelines. New Therapist, 58, 18-26. 